\title{
A FUNÇÃO DIDÁTICA DO TONTO NO LIVRO DE QOHÉLET
}

\author{
Cássio Murilo Dias da Silva \\ Pontifícia Universidade Católica do Rio Grande do Sul (Brasil) \\ cassiomu@gmail.com \\ https://orcid.org/0000-0002-8264-7793
}

Resumo: Este artigo estuda os textos em que Qohélet se refere ao tonto e à tontice. Serão analisadas a retórica, a sintaxe e as figuras de linguagem, bem como o desenrolar da argumentação. A crítica qoheletiana não é feita de modo orgânico, mas segue o ritmo por vezes caótico da vida real, talvez como estratégia para manter o discípulo/leitor atento e aberto a novas descobertas por conta própria. Nas várias facetas propostas por Qohélet, é possível vislumbrar o estrago que o tonto promove na sociedade. Como conclusão deste artigo, serão apresentadas uma breve sistematização e a importância do tonto na argumentação de Qohélet.

Palavras chave: Tonto. Estulto. Sábio. Qohélet. Eclesiastes.

\section{La función didáctica del tonto en el libro de Qohélet}

Resumen: Este artículo estudia los versos en los que Qohélet se refiere al tonto y a la tontería. Se analizarán la retórica, la sintaxis y las figuras del lenguaje, así como el desarrollo de la argumentación. La crítica qoheletiana no se hace de forma orgánica, sino que sigue el ritmo a veces caótico de la vida real, tal vez como una estrategia para mantener al discípulo / lector atento y abierto a nuevos descubrimientos por su cuenta. En las diversas facetas propuestas por Qohélet, es posible vislumbrar el daño que el tonto promueve en la sociedad. Como conclusión de este artículo, se presentará una breve sistematización y la importancia del tonto en el argumento de Qohélet.

Palabras clave: Tonto; Estúpido; Sabio; Qohélet; Eclesiastés. 


\section{The didactic function of the fool in the book of Qohelet}

Abstract: This article studies the texts in which Qohelet refers to fool and foolish. Rhetoric, syntax and figures of language will be analyzed, as well as the development of the argumentation. Qoheletian criticism is not done in an organic way, but follows the sometimes chaotic rhythm of real life, perhaps as a strategy to keep the disciple / reader watchful and open to new discoveries on their own. In the various facets proposed by Qohelet, it is possible to glimpse the damage that the fool promotes in society. As a conclusion of this article, a brief systematization and the importance of the fool in Qohelet's argument will be presented.

Keywords: Fool. Stupid. Wise. Qohélet. Ecclesiastes.

\section{Introdução}

Estulto, bobo, estúpido, besta, insensato, idiota, tolo, babaca, boçal, palerma, apalermado, mentecapto, imbecil, débil, paspalho... Uma consulta a um dicionário de sinônimos de qualquer língua moderna (português, castellano, inglês etc.) revelará muitos vocábulos para qualificar, com diversas nuanças, o mesmo tipo de indivíduo: o tonto.

Também o hebraico bíblico apresenta vários termos para "tonto" e sinônimos: hll, lēṣ, nābāl, ba ar, 'ěwîll, petî, sākāl, $k^{e}$ sîll. Este vocabulário foi abrangentemente analisado por Stephen A. Mandry, em sua tese doutoral There is no God!'”: A Study of the Fool in the Old Testament, particularly in Proverbs and Qoheleth ${ }^{1}$. Como parte das conclusões, Mandry sintetiza as características psicológicas e comportamentais dos indivíduos designados por cada termo, com uma larga contextualização no mundo extra-bíblico.

Faltam, no entanto, estudos mais aprofundados e específicos para cada livro sapiencial bíblico. Os dicionários de teologia bíblica, devido principalmente à exiguidade de espaço, dedicam somente algumas linhas ao tonto. Semelhantemente, os comentadores aos livros sapienciais bíblicos limitam-se a falar do tonto somente na interpretação dos versículos concernentes a este personagem, mas não elaboram estudo mais longo e sistemático.

Com o desejo de colaborar para suprir tal carência, este artigo aborda sistematicamente os versículos e as perícopes sobre o tonto e sua tontice

1 Defendida no Instituto Angélico, em Roma, em 1972, e publicada parcialmente (capítulos 4, 10 e 11) em MANDRY, There is no God! - A Study of the Fool in the Old Testament, particularly in Proverbs and Qoheleth. Roma 1972. 
no livro de Qohélet (também chamado de Eclesiastes) ${ }^{2}$. O ponto de partida é um questionamento de caráter funcional: Com qual finalidade persuasiva Qohélet se refere ao tonto? Dito de outro modo: se Qohélet quer inculcar em seus discípulos, ouvintes e leitores o desejo de se tornarem sábios, por que insiste em se referir a quem rejeitou a sabedoria?

Para responder a esta pergunta, serão abordados os vários aspectos das perícopes com afirmações sobre o tonto. A análise dos versículos e de seus contextos versará não somente sobre aspectos de conteúdo, mas também a retórica, a sintaxe, as figuras de linguagem e outros artifícios literários disponíveis ao autor, bem como sua função no desenrolar da argumentação.

Como se verá, Qohélet não poupa esforços para convencer seu discípulo/leitor de duas coisas. Em primeiro lugar, de que o tonto está em toda parte, é onipresente. Segundo, e esta é a intenção mais importante, de que quem quiser ser sábio poderá aprender muito com o tonto: basta observá-lo e... fazer diferente do que ele faz!

\section{O mosaico que retrata o tonto}

Embora a língua hebraica tenha várias palavras para dizer "tonto", Qohélet utiliza somente duas: $k^{e} s \hat{l} l$ (18 vezes) e sākāl (4 vezes). Na já citada tese doutoral de Mandry, estes dois tipos de indivíduos são assim qualificados ${ }^{3}$ :

$k^{e} s \hat{\imath} l: \quad$ Termo favorito para estulto, principalmente em Provérbios e Qohélet. Grande talento para mentir, caluniar, multiplicar palavras e enfurecer os outros. Hábil, fraudulento; mente arguta capaz de disfarçar sua "sabedoria" de verdadeira sabedoria. Extremamente autoconfiante. Rejeita punições e tentativas de discipliná-lo com jovial desprezo. Textos de Qohélet falam de rebeldia contra a religião.

$s \bar{a} k \bar{a} l$ : Normalmente encontrado em posição de destaque. Usa da autoridade para alcançar seu próprio bem-estar. Deliberadamente ultrapassa os limites de sua autoridade para atingir seus objetivos. O povo normalmente sofre por causa de sua loucura.

2 Este artigo é a elaboração final e completa de um estudo sobre a figura do tonto em Qohélet. Ao longo da pesquisa, pequenas partes foram apresentadas, como amostragem, em dois congressos acadêmicos e publicadas nos respectivos anais (cf. referências bibliográficas).

${ }^{3}$ MandRY, There is, 55-56. Há de se notar, porém, que os dicionários de hebraico bíblico dão poucas informações sobre as diferenças entre as palavras para dizer "estulto". 
Nota-se imediatamente que essas duas palavras não indicam pessoas desprovidas de inteligência ou de capacidade de raciocínio. O indivíduo por elas designado não é o "ignorante", o "imbecil", o "retardado", o "néscio", o "inexperiente". Não! As palavras $k^{e}$ sîl (neste artigo, "estulto") e sākāl (neste artigo, "idiota") qualificam pessoas que propositadamente se afastam da verdadeira sabedoria.

Em Qohélet, o uso de apenas dois vocábulos faz parte das várias estratégias que o autor do livro utiliza para dar vigor à sua argumentação. Outro artifício é a multiplicidade de recursos retóricos (comparações, sentenças-tôv, questões retóricas com respostas negativas, variadas figuras de linguagem e outras que serão discutidas in loco) para potencializar ainda mais a crítica qoheletiana ao tonto, seja ele estulto ou idiota. Um terceiro recurso é o fato de Qohélet não apresentar uma reflexão doutrinal sistêmica, e sim um grande mosaico: além de oferecer um retrato multifacetado do estrago que o tonto - seja ele alguém sem nenhuma importância, seja ele alguém revestido de poder e autoridade - promove na sociedade, tal mosaico mantém o discípulo/leitor atento e aberto a novas descobertas por conta própria. Há ainda outro recurso que, pelas razões que logo ficarão claras, será a primeira matéria aprofundada neste artigo: o uso dos termos abstratos.

\section{Os termos abstratos}

Além dos termos concretos kesîl - "estulto" e sākāl - "idiota", Qohélet utiliza também quatro termos abstratos, três deles exclusivos: hôlēlût I hôlèlôt - "insensatez" (5 vezes: 1,17; 2,3.12-13; 7,25; 10,1.13), siklût "idiotice" (7 vezes: 1,17; 2,12; 7,25; 9,3; 10,13) e sékel - "idiotismo" (1 vez: 10,6). Utiliza também késel - "estultice” (1 vez: 7,25). Não obstante sejam quatro termos diferentes, há certa justaposição do que caracteriza cada um desses atributos.

\subsection{Uma investigação radical e independente: Qo 2,12}

Para provar sua tese fundamental - "é tudo hébel - "vaidade, engano, mentira""4 -, Qohélet faz uma pesquisa de campo, que envolve investigar também (e principalmente) a sabedoria, a insensatez, a estultice e a idiotice:

\footnotetext{
4 Cf. mais adiante, nota 14.
} 
1,$17 ; 2,3 ; 7,25$. Qohélet imita inscrições reais do Antigo Oriente Próximo e se apresenta como um soberano que buscou incessantemente a sabedoria ${ }^{5}$. Em 2,12, ele afirma ${ }^{6}$ :

12a Voltei-me eu mesmo para observar sabedoria bem como insensatez e idiotice.

b Pois, o que (fará) o homem que virá depois do rei? O mesmo que há muito fizeram.

A língua hebraica não exige o uso dos pronomes pessoais. Aqui, porém, o uso de 'ănî - "eu" tem razões enfáticas: "eu mesmo", isto é, por mim mesmo, sem aceitar como pressuposto qualquer dogma sobre hokmâ - "sabedoria", siklût - "idiotice" e hôlēlôt - "insensatez". Em outras palavras, Qohélet afirma ter chegado às suas conclusões sem se basear no que a tradicional doutrina da retribuição atesta sobre estes assuntos.

Tal busca, porém, não é motivada pela mera curiosidade teórica, mas visa estabelecer o sentido prático da vida, servindo-se da observação direta $(2,12)$, da reflexão $(1,17 ; 7,25)$ e mesmo do prazer $(2,3)$. A oposição "sabedoria" versus "insensatez e idiotice" abrange a totalidade da experiência humana?.

Em 1,17, Qohélet fala de suas investigações a respeito desses mesmos assuntos, mas sem expor seus métodos nem suas conclusões. Em 2,12 , porém, ele anuncia os dois temas que tratará a seguir: uma discussão sobre a vantagem ou não da sabedoria sobre a insensatez e a idiotice (v. 12a); e uma reflexão sobre o herdeiro (v. 12b), respectivamente desenvolvidos em 2,13-17 e 2,18-23. Estas mesmas perícopes são também as únicas em todo o livro nas quais o tonto encontra-se direta ou indiretamente envolvido com Qohélet em primeira pessoa. Em ambas, não há vantagem para Qohélet.

5 Koosed, (Per)mutations, 89; KoH, Royal, 30-31.

6 Todas as traduções usadas neste artigo são feitas pelo autor, diretamente do texto hebraico.

7 Cf. Di Fonzo, Ecclesiaste, 143. Por sua vez, Gordis, Koheleth, 150 e 219-220, elimina do texto o $w^{e}$ de $w^{e}$ hôlēlôt e traduz: "Novamente eu vi que a sabedoria não é nada mais do que loucura e desatino". Os argumentos de Gordis: (a) na inteira seção (vv. 12-19, em sua divisão), o teor é negativo: a sabedoria não dá vantagem ao homem; (b) como muitas vezes no árabe, o duplo acusativo após um verbo de percepção indica identificação. A mesma interpretação é dada a 1,17, na p. 213. 


\subsection{Insensatez e trevas: Qo 2,13-14a}

O primeiro tema - o confronto sabedoria versus insensatez e idiotice - anunciado $3 \mathrm{~m} \mathrm{2,12} \mathrm{será} \mathrm{desenvolvido} \mathrm{em} \mathrm{dois} \mathrm{momentos} \mathrm{contrastantes:}$ no primeiro (2,13-14a), Qohélet conclui que a sabedoria é superior; no segundo momento (2,14b-17), Qohélet chega à conclusão contrária. Não que ele se contradiga, mas toma dois diferentes pontos de partida: como critério de discernimento quotidiano, a sabedoria revela-se um caminho melhor do que a insensatez e a idiotice; isso, porém, não evita que, diante da morte, sábio e estulto se encontrem em igual situação.

Por ora, apenas o primeiro momento: a superioridade da sabedoria, em Qo 2,13-14a:

13a E observei por mim mesmo
que há vantagem da sabedoria sobre a idiotice,
b como a vantagem da luz sobre as trevas
14a O sábio: os seus olhos estão na cabeça;
mas o estulto, nas trevas ele caminha;

Os termos abstratos hokmâ - "sabedoria" e siklût - "idiotice" como objeto da pesquisa qoheletiana reaparecem no início do relatório da investigação. A vantagem da luz sobre as trevas (v. 13b) não só explica a vantagem da sabedoria sobre a idiotice (v. 13a), mas também a vantagem do $h \bar{a} k \bar{a} m$ - "sábio" e do $k^{e} s \hat{l} l$ - "estulto". A frase "seus olhos estão na cabeça" equivale a "caminhar na luz". No hebraico, é formulada sem o verbo e enfatiza a qualidade do sábio: o discernimento prático e moral é parte natural de sua personalidade ${ }^{8}$. Diferentemente, a descrição do estulto, por meio de um verbo no particípio, ressalta o caráter contínuo e ininterrupto de sua ação viciada: o estulto caminha continuamente nas trevas ${ }^{9}$, é alguém sempre e totalmente sem rumo. Mais ainda, ao equiparar sabedoria e luz, Qohélet retoma uma convenção tradicional - sabedoria é luz, luz é vida (Pr 6,23; Sal 119,105) -, o que torna o contraste entre o sábio e o estulto ainda mais forte: o sábio caminha para a vida, o estulto caminha para a morte ${ }^{10}$.

8 Cf. Di Fonzo, Ecclesiaste, 153; Ogden, Qoheleth, 44; Vílchez Líndez, Ecclesiastes, 199. Rashi, citado por Zlотоwitz, Kohélet, 74, traduz rō'š (literalmente: “cabeça”) por "início", e interpreta: "o sábio prevê o resultado de seus atos antes de iniciá-los".

9 Cf. Gesenius - Kautzsch - Cowley, Grammar, §116a (p. 356); WaltKe - O’Connor, Introduction, 36.1d (p. 613).

$10 \mathrm{~K}$ IM, Reanimating, 179; Morla Asensio, Eclesiastés, 51. 


\subsection{Pequenas idiotices, grandes tragédias: Qo 10,1}

Embora Qohélet seja um mestre convicto da superioridade da sabedoria, não é alienado: ele sabe muito bem que a sabedoria é frágil e continuamente ameaçada pela estultícia. Tal ameaça mostra sua força na realidade prática: na dinâmica quotidiana da vida, a estultícia pode demolir tudo o que a sabedoria constrói. Com uma vivaz imagem poética, Qohélet assim o ilustra em 10,1:

la Moscas mortas tornam fétido, fazem fermentar um óleo preparado.

b Mais valorizada do que a sabedoria e do que a glória é uma pequena idiotice

Em 10,1b, encontra-se uma afirmação com as mesmas características de uma sentença-tôv, mas com duas variações:

a) a fórmula não é o habitual țôb min - "melhor do que" (Pr 16,32; 17,1; Qo 5,4 etc.), e sim yāqār min - "vale mais do que";

b) a ordem dos elementos é inversa, ou seja, o termo sobre o qual se afirma a vantagem aparece em segundo lugar.

A raiz yāqār - "ser mais valioso" pode exprimir um juízo subjetivo, ou seja, o valor dado por alguém ao objeto considerado, com o sentido de "amado", "estimado"11 e, portanto, algo que exerce influência. De fato, o v. 1 b não afirma que "um pouco de estultícia é melhor (țôb) do que uma honorável sabedoria", e sim que "tem mais peso" ou que "recebe maior valor" (yqr). Esta situação paradoxal torna-se ainda mais amarga quando se leva em conta que a certeza positiva formulada rapidamente $(9,18$ a) é logo seguida por uma constatação negativa longamente ilustrada $(9,18 \mathrm{~b}-10,1)$.

\subsection{Sob o domínio do idiotismo: Qo 10,6}

Não obstante o lēb - "coração/mente" do idiota falhe constantemente (cf. o comentário a Qo 10,2-3, mais adiante em 3.8), isso não impede que

11 Cf. Wagner, “華yāqar", 280; Clines, Dictionary. IV, 275; VanGemeren, Dictionary. II, $522-523$ 
seu discurso lhe garanta algum sucesso, o que aumenta ainda mais o assombro de Qohélet, como afirmado em 10,6:

6a Ao idiotismo é dado [lugar] nas grandes alturas,

b mas os ricos se sentam no [lugar] inferior.

A oposição “ăš̂̀r - "rico" versus sākāl - "idiota" é típica do sistema da retribuição, no qual o pobre é ao mesmo tempo estulto, preguiçoso, ímpio e maldito por Deus, enquanto o rico é sábio, trabalhador, justo e bendito ${ }^{12}$. O texto massorético, no entanto, utiliza o abstrato sekel - "idiotismo" em lugar do concreto sākāl - “idiota”. Tal substituição pode ter finalidade retórica enfática: não se trata de um idiota qualquer, mas alguém "extrema ou intensamente idiota" ". Além disso, a escolha do abstrato tem uma dupla função retórica: designar os ministros e exprimir o juízo de Qohélet a respeito do governo descrito: sua característica geral é sekel "idiotismo"!

Por outro lado, há de se notar que o termo sekel - "idiotismo" não designa o objeto da crítica, mas o juízo sobre os efeitos de uma administração ruim, qualificada como $\grave{s}^{e} g \bar{a} g \hat{a}$ - "erro, imprudência”, isto é, um modo de governar totalmente irresponsável. Com efeito, conferir poder ao idiotismo é somente o reflexo de uma autoridade já exercida idiotamente, uma vez que um soberano sábio trataria de evitar esse mal.

12 Cf. PIottı, “Osservazioni”, 134; Gordis, Koheleth, 320; GordIs, “Social”, 113; KIM, Reanimating, 181. Por sua vez, Dı Fonzo, Ecclesiaste, 292, prefere corrigir para o termo concreto e dar uma dupla explicação. Segundo ele: (a) "estulto" encontra-se em lugar de "pobre" "graças ao respeito que Qohelet demonstra pelo 'pobre e sábio'” que, poucos versículos acima, salvara sua cidade; e (b) para Qohelet, "teria sido demais... pedir que se colocassem nos postos de governo exatamente os 'sábios'... dada a pouca estima demonstrada pelos governantes em geral". Diferentemente, SACCHI, Qoelet, 205 [745], que também corrige para o termo concreto, pensa que a única explicação para o uso de sākāl - "idiota" seja considerar Qohelet "um conservador que não veja com bons olhos o pobre, o 'ebyôn, instintivamente igualado ao estulto".

13 Assim GinsBurg, Coheleth, 428. Para este mesmo estudioso, a falta do artigo em rabîm - "muitos, grandes" indicaria que tal termo é uma adição adverbial a bamrômîm - "nas alturas, nos lugares altos": "muitos cargos de responsabilidade outorgados ao estulto", uma vez que a interpretação "postos muito altos" exige o artigo. Menos assertivo, VílChez Líndez, Ecclesiastes, 374, prefere o abstrato "para que o recurso não perca sua força expressiva". Na opinião de Dı Fonzo, Ecclesiaste, 291, os massoretas assim vocalizaram "talvez para designar um grande número de estultos" designados pelo termo abstrato. 


\subsection{A perversidade da insensatez: Qo 10,12-15}

A derradeira reprovação de Qohélet ao comportamento que o discípulo/leitor deve evitar encontra-se em 10,12-15 e, semelhante a 5,2-3; 7,56 e 10,3, refere-se ao muito tagarelar do estulto:

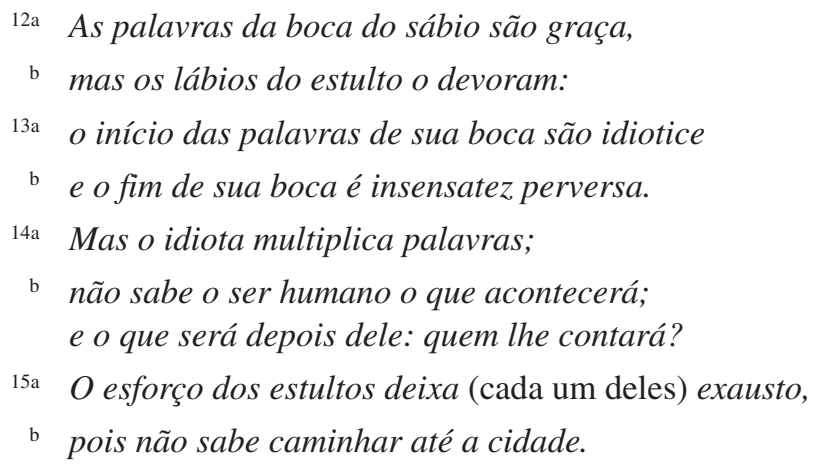

Em todo o livro, esta é a primeira e única vez que os termos hạkām - "sábio", $k^{e} s \hat{\imath} l$ - "estulto", sākāl - "idiota", siklût - "idiotice" e hôlèlût "insensatez" estão concentrados na mesma subunidade (em 2,12-17 faltava $s \bar{a} k \bar{a} l$ - "idiota"). Por outro lado, é também a última vez que Qohélet os utiliza, uma vez que não mais falará do tonto (estulto ou idiota) nem do sábio ${ }^{14}$.

Estes versículos serão abordados com maiores detalhes quando se falar do discurso e da incapacidade do estulto-idiota (cf. mais adiante, em 3.9). Por ora, basta observar o arranjo quiástico das palavras que designam o tonto e suas "qualidades":

\begin{tabular}{|c|c|c|}
\hline$k^{e} s \hat{\imath} l$ & v. 12 & estulto \\
\hline siklût & v. 13 & idiotice \\
\hline tôlēlût & & insensatez \\
\hline$s \bar{a} k \bar{a} l$ & v. 14 & idiota \\
\hline$k^{e}$ sîlim & v. 15 & estultos \\
\hline
\end{tabular}

A única palavra sem termo correspondente está no centro do quiasmo e funciona como qualificação e juízo: em seu tagarelar, o tonto manifesta a sua insensatez.

14 O termo ḥākām - "sábio" aparecerá ainda duas vezes no primeiro epílogo redacional (12,9-11): primeiro, para qualificar Qohélet; depois, na comparação acerca dos ensinamentos ("as palavras") do sábio. 


\subsection{Síntese e paradoxos}

Ao criticar idiotice e insensatez, Qohélet apresenta-se como alguém que fala com propriedade porque as investigou profundamente $(1,17 ; 2,13$; $7,25)$ e até se entregou à idiotice como uma experiência de pedagogia reversa $(2,3)$. As conclusões são as já esperadas: idiotice e insensatez são perversas e fazem multiplicar as palavras que levam a um fim trágico $(10,13)$. Não obstante, Qohélet tem consciência de dois amargos paradoxos: qualquer idiotice é mais valorizada do que a sabedoria $(10,1 \mathrm{~b})$ e o fato de o poder ser entregue ao idiotismo $(10,6)$, e não ao sábio.

\section{O estulto}

O principal termo usado por Qohélet para definir o tonto é $k^{e} s \hat{\imath} l$ - "estulto" (18 vezes: 2,14-16; 4,5.13.17; 5,2-3, 6,8; 7,4-6.9; 9,17; 10,2.12.15), por vezes justaposto a $s \bar{a} k \bar{a} l$ - "idiota” (assim em 10,3 e 10,12-15). Nas várias situações em que Qohélet o insere, o estulto é sempre um elemento perturbador.

\subsection{O mesmo destino para o sábio e para o estulto: Qo 2,14b-17}

Em 2,12, Qohélet afirma fazer uma investigação independente acerca da hokmâ - "sabedoria", da hôlēlôt - "insensatez" e da siklût - "idiotice". Sua primeira conclusão está nos vv. 13-14a: a sabedoria é mais vantajosa do que a idiotice, o hạa kam - "sábio" leva vantagem sobre o $k^{e}$ sîl - "estulto" (cf. anteriormente, 2.2). O relatório da investigação, porém, continua e o segundo tema anunciado em 2,12 é desenvolvido nos vv. 14b-17:

14b E entendi também eu mesmo que um só destino cabe a todos eles.

15a E disse eu mesmo em meu coração: Como o destino do estulto também eu estou destinado. Então, por que me tornei eu mesmo sábio? Qual a vantagem?

b E afirmei em meu coração que também isto é vaidade.

16a Pois não há lembrança para o sábio exatamente como o estulto eternamente.

b Imediatamente nos dias que virão, tudo será esquecido. Então, como?... Morre o sábio exatamente como o estulto!?

17a Então odiei a vida, pois há um mal sobre mim: a obra que fiz debaixo do sol.

b Sim! Tudo é vaidade e aflição de espírito. 
Estes versículos apresentam uma visão contraposta à afirmação do v. 14a. Diante do miqreh - "destino", não há vantagem do sábio sobre o estulto. A centralidade do "eu" de Qohélet e o seu gradativo envolvimento na averiguação acerca da sabedoria e da idiotice faz com que o raciocínio siga duas linhas: a da definição (vv. 14 e 16) e a da autoidentificação (vv. 15 e 17).

A linha da definição compreende os vv. 14b e 16, nos quais as afirmações são impessoais e neutras. Qohélet define o que chama de "destino": a morte e o esquecimento. Neste destino comum ao sábio e ao estulto, o que mais pesa a Qohélet não é a morte em si mesma, mas sua consequência, que será imediata e inexorável: o total cancelamento da memória. Por isso, a morte se torna uma obsessão para Qohélet ${ }^{15}$. Eis por que a última frase do v. 16 é uma pergunta retórica na qual a partícula interrogativa inicial revela o desconcerto de Qohélet: 'êk - “como!?”.

Mas, Qohélet não consegue manter-se totalmente alheio à problemática do destino. Antes, vê-se obrigado a considerar sua própria situação, o que o leva à segunda direção do raciocínio: a identificação pessoal e passional, nos vv. 15 e 17.

No v. 15, de dois modos diferentes e complementares, Qohélet assevera que não pertence ao grupo dos estultos: na afirmação "o destino do estulto é o mesmo meu", e na questão retórica "por que me tornei sábio?", que abre passagem para o refrão "isso também é hébel - "vaidade, engano, vazio, mentira" 16 .

Em outras palavras, a conquista da sabedoria é frustrante: embora tenha se tornado sábio, Qohélet continua semelhante a um estulto, uma vez que, exatamente como um estulto, morrerá e será esquecido.

Qohélet se reconhece incapaz de suportar tal paradoxo: "então odiei ${ }^{17}$ a vida" (v. 17); "eu odiei todo o meu trabalho" (v. 18).

15 Koosed, (Per)mutations of Qohelet, 90.

16 Para minha interpretação sobre o significado de hébel - "vaidade, engano, mentira", cf. meu artigo "Universos virtuais bíblicos" (conferir bibliografia final) e, de modo mais sistemático, SiLva e Ló, Caminho, 83-90. Em meu entendimento, o termo hébel aplica-se aos ensinamentos da tradicional doutrina da retribuição e os qualifica como "engano, falsidade... mentira". Neste caso, a doutrina tradicional apregoa que o sábio terá uma retribuição superior à do estulto; Qohélet afirma ao contrário: “isso também é mentira, engano, fumaça... é hébel!

17 Jenni, “שנא śn' Odiar”, 1049-1052; Clines, Dictionary. VIII, 168b; VanGemeren, Dictionary. III, 1257-1258: śn' = "detestar, ter repugnância”. Descarta-se para este versículo o sentido mais atenuado "não gostar, evitar, sentir antipatia, desprezar", por dois motivos. Primeiro, porque o simples desprezo já fora expresso no v. 15b: "considerei também isso hébel 'vaidade, mentira' ", enquanto após śn' - “odiar”, empre- 


\subsection{O estulto destrói a si mesmo: Qo 4,5}

No âmbito da oposição sabedoria versus insensatez e idiotice, o tema do 'āmāl - "trabalho-esforço" havia ocupado vários versículos do capítulo 2 (vv. 18-23). Em Qo 4,4-6 ele retorna, agora sobre o pano de fundo da oposição entre dedicação e indolência. A figura do estulto aparece no v. 5:

5a O estulto cruza suas mãos
b e devora sua (própria) carne.

Unanimemente, os comentadores leem o v. 6 como uma defesa do equilíbrio ou do justo meio, a aurea mediocritas, entre o trabalho excessivo provocado pela inveja e a preguiça do estulto. A argumentação se desenvolveria dialeticamente:

- tese: excesso - inveja (v. 4);

- antítese: preguiça - autodestruição (v. 5);

- síntese: moderação (v. 6).

Nesta interpretação, a expressão kap nāhat - "mão com descanso" (v. 6) equivale a "trabalhar moderadamente, mas trabalhar", o que seria não só uma crítica ao trabalho excessivo, mas também ao nenhum trabalho do estulto. Entretanto, esta interpretação é problemática, pois supõe que tanto no primeiro como no segundo membro da sentença-tô $v^{18}$ haja uma concessão implícita, na qual se recomenda não praticar nenhum dos extremos: evitar não trabalhar nada (primeiro membro) e, inversamente, evitar trabalhar demais (segundo membro).

Nitidamente, o v. 5 interrompe a crítica à inveja e ao excesso de trabalho que ela provoca, e cumpre uma dupla função: criticar a falta de trabalho (e quem a pratica) e criticar o estulto. Em outras palavras, a crítica ao estulto não se dá no v. 6 , e sim no próprio v. 5 !

Note-se que aqui o termo $k^{e}$ sîl - "estulto" é utilizado com um significado muito preciso, dado pelo contexto: "estulto" equivale a "preguiçoso" "19. Graças a esta identificação, o v. 5 funciona de modo ambíguo: o estulto é preguiçoso e, vice-versa, o preguiçoso é estulto. Seja lá qual for o

ga a fórmula longa hébel ûr ût rûah - "vaidade e correr atrás do vento". Segundo, porque o movimento in crescendo dos verbos nos vv. 13-17 exige um sentimento mais forte e que envolva mais profundamente o autor.

18 Sentença-tôv: comparação valorativa, assim formulada: "melhor $x$ do que $y$ ".

19 Em conformidade com a tradição sapiencial: $\operatorname{Pr} 10,4-5 ; 12,24.27 ; 13,4 ; 15,19$; 16,$26 ; 19,15 ; 20,4 ; 24,30-34$; e principalmente $6,6-11$ e $26,13,16$. 
sujeito criticado e seja qual for a crítica feita a ele, o juízo é perfeitamente válido em ambas as direções.

Por outro lado, Qohélet não considera sábio quem cai no extremo oposto e trabalha demais. Ao contrário, afirma: "todo trabalho" é também vaidade e correr atrás do vento" (4,4, retomado no v. 8). Em outras palavras, trabalhar demais é outra forma de estultícia!

\subsection{Ancião, mas estulto: Qo 4,13}

Em 4,13-14, Qohélet questiona o vínculo entre idade e sabedoria: nem sempre ser ancião equivale a ser sábio. A referência ao estulto encontra-se no v. 13:

13a Melhor um jovem pobre mas sábio,

b do que um rei ancião mas estulto, que não sabe mais ser aconselhado.

O curioso nesta formulação é que, no segundo elemento da sentença-tôv, o termo de referência já não é mais o oposto de yeled - "jovem" (zāqēn - "ancião, velho"), e sim o oposto de miskèn - "pobre", isto é, melek - "rei".

Embora os termos $k^{e} s \hat{l} l$ - "estulto" e hạa kàm - "sábio" possuam aqui um nítido valor de adjetivo (aliás, não comum em Qohélet), a oposição construída com eles não é problemática: a questão de fundo é a superioridade da pessoa sábia sobre a estulta.

Algo diferente, porém, ocorre com as outras palavras: o substantivo yeled - "jovem" opõe-se ao adjetivo zāqēn - "ancião, velho", enquanto o adjetivo miskēn - "pobre" contrapõe-se ao substantivo melek - "rei". Esta forma de construir os antagonismos enfatiza a ruptura com a doutrina tradicional da retribuição - sabedoria unida a riqueza (e sucesso) oposta à estultícia unida a pobreza -, pois reforça a dissociação entre sabedoria e velhice. Em outras palavras, quando se trata de ser sábio, muitas vezes a idade é algo relativo.

A partícula 'ôd (literalmente: "mais, ainda"), última palavra do v. 13, enfatiza a ideia de continuidade, repetição e persistência ${ }^{20}$, além de acrescentar à crítica um elemento de orgulho, que acentua drasticamente a estultícia do rei ancião: apesar (ou, justamente por causa?) de sua idade avançada, não sabe mais aceitar as advertências (conselhos) de outras pessoas.

20 Cf. Brown - Driver - Briggs, Lexicon, 729; Clines, Dictionary. VI, 292. 


\subsection{O estulto e o culto: Qo 4,17; 5,2.3}

A subseção 4,17-5,6 distingue-se da anterior por suas características formais (novo vocabulário, tom parenético e imperativos, predomínio da segunda pessoa) e por um novo tema (a prática religiosa). O pano de fundo é a relação tu - Deus.

Os versículos 4,17a a e 5,6b funcionam como uma espécie de inclusão e relacionam-se por meio de um paralelismo sintético, no qual o segundo membro $(5,6 \mathrm{~b})$ explicita o primeiro $(4,17 \mathrm{a} \alpha)$ :

\section{4,17a Guarda teus pés quando caminhas à casa de Deus 5,6b Sim, teme a Deus.}

As atividades desenvolvidas na casa de Deus são três: sacrifício $(4,17 \mathrm{a} \beta$ b), oração (5,1-2) e promessa (5,3-4). Sobre cada uma delas Qohélet faz ao menos uma observação envolvendo o estulto. Mais do que descrever o comportamento do estulto, Qohélet admoesta o discípulo/leitor a não o imitar.

\subsubsection{O sacrifício dos estultos: Qo 4,17}

Mesmo sem o termo tộb - "melhor" inicial, 4,17aß é uma afirmação do tipo sentença-tôv:

\section{7aß E (é melhor) aproximar-te para escutar}

do que para apresentar o sacrifício dos estultos.

O texto não condena o sacrifício, mas a forma com que é realizado, por meio de um genitivo de autor: "o sacrifício dos (= realizado pelos) estultos".

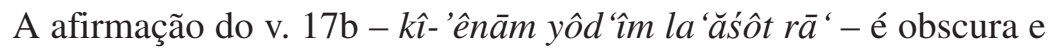
provocou certa controvérsia entre os comentadores ${ }^{21}$ : os estultos...

${ }^{21}$ Um dos pontos discutidos é se o texto deve ser emendado ou aceito como está, embora isso exija uma interpretação que o torne plausível. Cf. o debate em GoRDIS, Koheleth, 247-248; Delitzsch, Commentary, 283-284; Dı Fonzo, Ecclesiaste, 198. Segundo Morla Asensio, Eclesiastés, 78, “Qohélet afirma que quem dá mais valor ao sacrifício" do que à obediência "é néscio, porque não percebe que avaliação que faz 'está mal', o que equivale a perpetrar o mal". As interpretações rabínicas também acentuam a estupidez dos estultos: segundo Levi ben Gershom, rabino francês dos séculos XIII-XIV, os estultos "pecam e depois usam suas transgressões como pre- 
(a) ... não sabem "nem sequer agir mal"?

(b) ... não sabem "senão agir mal"?

(c) ... não sabem "que agem mal"?

A palavra $r \bar{a}$ " - "mal" é usada 16 vezes em Qohélet. Na maioria dos casos, ela descreve não um ato moralmente mau, e sim algo desastroso, uma ação feita sem reflexão e que pode provocar uma calamidade $(1,17 ; 2,17$; 4,$8 ; 5,13$ etc.). Seja qual for a interpretação assumida, trata-se de uma frase altamente irônica: os estultos são tão tontos que...

(a) ... não são capazes nem mesmo de fazer maldades; ou...

(b) ... só sabem provocar calamidades; ou...

(c) ... fazem bobagem e não percebem.

Em resumo, Qohélet propõe ao discípulo/leitor uma ironia dramática que ressalta a completa incompetência dos estultos.

\subsubsection{A oração do estulto: Qo 5,2}

Não somente o sacrifício do estulto é reprovável; mas também seu modo de rezar. Qo 5,2:

2a Com efeito, o sonho vem com muitos afazeres,

b e a voz do estulto com muitas palavras.

Na crítica à oração de estulto, dois são os conselhos básicos: não ter pressa de abrir a boca $(5,1 \mathrm{a})$ e, uma vez aberta, não multiplicar palavras (5,1b-2).

Latente ao paralelismo ḩălôm - "sonho, devaneio" - qôl kesîl - "voz do estulto" está a ideia de que oração do estulto afasta-se da seriedade tal como o sonho da realidade.

A antítese $d^{e}$ bārîm m me ațîm - "poucas palavras" versus rōb d'bārîm "muitas palavras, palavras demais" caracteriza o sábio (e piedoso) como aquele que, diante de Deus, fala pouco e com sinceridade; ao contrário, o estulto (e ímpio) é prolixo e não dá atenção às insensatas palavras que profere.

texto para oferecer sacrifícios, achando que Deus gosta de suas oferendas"; já Ye'hiel Hillel ben David, comentador do século XVIII, interpreta assim a frase "não sabem que fazem o mal": "eles nem sequer tentam compreender as implicações de sua má conduta. Em sua loucura, eles pensam que Deus fica feliz quando pecam e oferecem um sacrifício expiatório". Ambos citados por ZLoTowitz, Kohélet, 108. 


\subsubsection{A promessa dos estultos: Qo 5,3}

Quem muito fala para rezar, muito fala também para fazer votos e promessas. Também sob este aspecto, o comportamento religioso dos estultos não é um bom exemplo ser seguido. Qo 5,3:

3a Quando fizeres um voto a Deus, não demores em cumpri-lo, pois ele não gosta dos estultos.

b $O$ que prometeste, cumpre-o!

A combinação dos verbos $n d r$ - "fazer voto, prometer" e šlm - "cumprir" funciona como expressão polar e domina a exposição da terceira prática religiosa. $\mathrm{O}$ estulto tem uma característica bem definida: é alguém que faz votos e não os cumpre; o estulto fala em excesso e acaba prometendo até o que não pode nem tem sinceras intenções de cumprir (cf. vv. 1-2). A reação divina - "não gostar, não ter prazer" - conduz inevitavelmente à sentença-tôv do v. 4.

A dupla recomendação inicial de "não ter pressa" em multiplicar palavras diante de Deus (v. 1) transforma-se em "não demorar" em cumprir os votos feitos (v. 3). Deste modo, acentua-se, mais uma vez, a necessidade de falar com sabedoria e prudência.

\subsection{Insatisfação geral, do sábio e do estulto: Qo 6,8}

Qo 6,1 anuncia algo sombrio: um grande mal sobre todo ser humano. A subseção 6,1-9 explicita o conteúdo do "grande mal":

$$
\begin{array}{lll}
\text { v. } 2 & \text { sua alma } & \text { Deus não permite a ela comer } \\
\text { v. } 3 & \text { sua alma } & \text { não se sacia } \\
\text { v.7 } & \text { a alma } & \text { não se satisfaz }
\end{array}
$$

Estas afirmações sobre a não satisfação/saciedade da nepeš - "alma, apetite" preparam a questão retórica do v. 8:

8a Pois, qual a vantagem do sábio sobre o estulto?

b Qual do pobre que sabe caminhar em meio aos vivos?

A construção sintática no hebraico é do tipo dativus incommodi, isto é, indica a desvantagem de alguém na situação descrita. Qohélet afirma que o sábio não tem nenhuma vantagem sobre o estulto, não somente na morte (como afirmava 2,14-17), mas também já durante a vida, uma vez que am- 
bos dividem a mesma frustração: tanto de um como de outro, hanepeš lô ' timālè - "a alma não se enche (= não se satisfaz)". Nesta perspectiva, sábio e estulto encontram-se em iguais condições.

\section{6. É melhor ser sábio do que ser estulto: Qo 7,4}

Os vários ensinamentos agrupados em 7,1-14 apresentam um elenco do que Qohélet considera o melhor para o homem. A concentração de sentenças-tôv nos vv. 1.3.5.8 constitui um dos elementos unificadores desta subseção.

\subsubsection{O coração dos estultos: Qo 7,4-6.9}

Os primeiros quatro versículos afirmam que o luto é mais instrutivo do que a alegria. No v. 3, Qohélet não identifica tristeza e sabedoria; o sentido é outro: sábio sabe aproveitar os momentos de crise (tal como a morte) para refletir e encontrar o significado profundo de cada acontecimento ${ }^{22}$.

Deve-se destacar o engenhoso e sutil raciocínio, que funciona de modo subliminar:

$\begin{array}{cc}\text { V. 2a } & \text { V. 4 } \\ \text { melhor } & \text { o coração dos sábios } \\ \text { caminhar para a } & \text { na } \\ \text { casa do luto } & \text { casa do luto } \\ \text { do que } & \text { o coração dos estultos } \\ \text { caminhar para a } & \text { na } \\ \text { casa do banquete } & \text { casa da alegria }\end{array}$

22 Cf. Ogden, Qoheleth, 103; Sacchi, Qoelet, 178 [735]; Ravası, Qohelet, 234-235. Nesta mesma linha, Vílchez Líndez, Ecclesiastes, 301 e, logo mais adiante, na p. 303 : o sábio é uma "pessoa madura e plenamente consciente e responsável"; o "néscio" é uma "pessoa imatura, vã e superficial". E ainda Morla AsEnsıo, Eclesiastés, 167, nota 22: “É evidente que Qohélet não rechaça a alegria e o desfrute como tais, mas apenas quando são adotados como resposta cega aos dissabores da vida [...] Neste sentido, a alegria se converte em uma atitude oposta a uma reta sabedoria". Diferentemente, na opinião de GoRDIs, Koheleth, 268, Qohélet "apenas afirma que uma face triste reflete uma mente sábia". 
Eliminando os termos equivalentes (evidenciados no diagrama), o que resta impresso no inconsciente é:

\begin{tabular}{c|c} 
v. $2 \mathrm{a}$ & v. 4 \\
\hline melhor & o coração dos sábios \\
do que & o coração dos estultos
\end{tabular}

Tendo reinvocado as figuras do ḥākām - "sábio" e do $k^{e} s \hat{\imath} l$ - "estulto", o v. 4 fornece também a ponte para duas novas reflexões sobre estes dois personagens: o discurso do sábio e o discurso do estulto (vv. 5-6) e a fragilidade do sábio (vv. 7-10).

\subsubsection{A gargalhada do estulto: Qo 7,5-6}

A conclusão latente dos vv. 2a e 4 leva uma consequência prática, reforçada por uma comparação breve, mas mordaz. Qo 7,5-6:

\footnotetext{
5a Melhor escutar a repreensão do sábio

b do que alguém que escuta o canto dos estultos.

6a Pois como o rumor dos espinhos debaixo do caldeirão, assim é a gargalhada do estulto.

b Isto também é vaidade!
}

Os dois genitivos de autor - šîr ke sîlîm - "canto dos estultos" (v. 5b) e śehốq hak silîm - "gargalhada do estulto" (v. 6a) - servem para avaliar negativamente o canto e a gargalhada.

No v. 5, é curioso o contraste singular ( hākēm - "sábio") versus plural (kesilîm - "estultos"): um único sábio tem mais peso do que muitos estultos ${ }^{23}$.

No v. 6a - kî ke qôl haśîrîm taḥat hasî̀r kēn śeḥôq hakesîl - "Pois como o rumor dos espinhos debaixo do caldeirão, assim é a gargalhada do estulto" - pode haver uma onomatopeia: o som da frase em hebraico reproduz o barulho de gravetos crepitando numa fogueira ${ }^{24}$. Assim é a gargalhada do estulto: um barulho que não dura nem produz efeito algum.

23 Cf. Ogden, Qoheleth, 104.

${ }^{24}$ Cf. Ogden, Qoheleth, 104; Dı Fonzo, Ecclesiaste, 228; Ravası, Qohelet, 236; TAmez, Cuando, 153; Morla Asensio, Eclesiastés, 115 e a maioria dos comentadores. 


\subsubsection{A ira do estulto: Qo 7,9}

Os vv. 7-10 são caracterizados por uma série de afirmações e recomendações sobre a disposição interior (vv. 7-8.9a) e por duas advertências negativas (vv. 9a.10). Como se pode observar, a composição literária do v. 9 serve como gancho para a sequência desses elementos. Qo 7,9:

9a Não te apresses em teu ânimo em irar-te,
b pois a ira se aloja no íntimo dos estultos.

Três diferentes termos - lēb - "coração, mente", $r \hat{u}^{a} h$ - "ânimo, espírito" e hêeq - "íntimo, seio" - designam a sede da disposição interior. Por meio deles, o texto apresenta um progressivo enfraquecimento do domínio da razão e da vontade sobre a impulsividade, e com eles caracteriza três diversos tipos de pessoa - o sábio, o discípulo, o estulto - que têm em comum a fragilidade:

v. 7: o lēb - "coração, mente" do sábio é ameaçado pelo suborno;

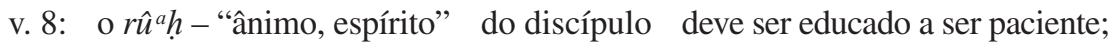

v. 9: o hê q - "íntimo, seio" dos estultos é caracterizado pela irritação ${ }^{25}$.

\subsection{Um grito entre os estultos: Qo 9,17}

Após a parábola acerca do homem sábio pobre que salva a cidade, mas que é esquecido $(9,13-15)$, o pensamento progride por meio da alternância de perspectivas. Qo 9,17:

17a As palavras dos sábios na calma são ouvidas,

b mais do que o grito de quem governa entre os estultos

Ao comparar sabedoria e força, Qohélet tem um juízo otimista: a sabedoria é melhor! Todavia, quando se recorda do exemplo anteriormente citado, este mesmo Qohélet conclui negativamente: aquele sábio foi des-

25 Morla Asensio, Eclesiastés, 116-117, prefere traduzir ka'as por “aflição, desgosto" e ligar o v. 9 aos seguintes: a pergunta "Por que os dias antigos são melhores do que os de agora?" (v. 10a) equivale mais a um ânimo deprimido do que a um espírito irado. 
prezado! Mas, voltando a alargar seus horizontes, ele muda novamente de perspectiva e o balanço é positivo: as palavras dos sábios são ouvidas.

A antítese nahat - "calma" - $z^{e}$ caqâ - "grito" se faz inda mais irônica, caso $z^{e}$ 'aq - "grito" tenha aqui seu valor primário e habitual: grito de desespero ${ }^{26}$. É como se Qohélet afirmasse: "governar estultos é desesperador"!

Quanto aos sábios, eles não perdem seu tempo em falar aos estultos, e por isso suas palavras são pronunciadas e escutadas de modo sereno ${ }^{27}$.

\subsection{O estulto-idiota se expõe ao ridículo: Qo 10,2-3}

Ao longo do livro, Qohélet opera uma fusão, de modo a não ser mais possível distinguir o $k^{e}$ sîl - "estulto" do $s \bar{a} k \bar{a} l$ - "idiota". O que até agora era algo subentendido, passa a ser explícito. Em 10,2-3, Qohélet justapõe os dois tipos de tonto:
2a O coração do sábio vai para a sua direita
2b mas o coração do estulto vai para a sua esquerda.
3a E mesmo no caminho pelo qual o idiota caminha seu coração falha
3b E diz de todos: "Ele é um idiota”!

Em 9,13-15, Qohélet narra uma parábola perturbadora: um homem sábio e pobre salva uma cidade, mas é totalmente esquecido. Este paradoxo leva Qohélet a refletir sobre alguns aspectos da estultícia: não obstante tudo, a sabedoria lhe é preferível e superior. Para provar isso, Qohélet passa a considerar o comportamento concreto do sábio e do tonto, agora duplamente caracterizado: $k^{e} s \hat{\imath} l$ - "estulto" e $s \bar{a} k \bar{a} l$ - "idiota".

Por meio do contraste lēb ḩākām - "o coração do sábio" versus lēb $k^{e} \hat{s i l}$ - "o coração do estulto", Qohélet reinvoca uma lição já dada anterior-

${ }^{26} 0$ significado primário da raiz z'q é "gritar por ajuda em meio a uma situação de desespero ou angústia"; por conseguinte, $z^{e}$ ‘ãqâ significa primeiramente "grito

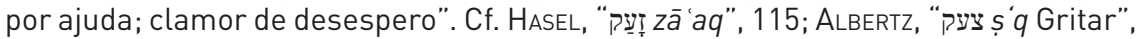
715-716; Koehler - Baumgartner, Lexicon. I, 277; Clines, Dictionary. III, 127-129; VanGEMEREN, Dictionary. I, 1131.

${ }^{27} 0$ acento disjuntivo tifha liga benaḥat - "na/com calma” a dibrê hăkāmîm - "palavras dos sábios". Na opinião de Delitzsch, Commentary, 370, o contraste nahat “calma" versus $z^{e}$ ‘āqâ - "grito" exige que "atribuamos a tranquilidade ao próprio sábio, e não aos seus ouvintes". Para a discussão do sentido deste versículo de difícil interpretação, cf. Dı Fonzo, Ecclesiaste, 285-286. 
mente (7,2-4), na qual levara seu discípulo/leitor a concluir que o primeiro (coração/mente do sábio) é superior ao segundo (coração/mente do estulto). Em 10,2, os termos "direita" e "esquerda" indicam, respectivamente, a "decisão/via justa" e a "decisão/via errada", de modo a afirmar que ao tonto falta o discernimento que o sábio possui. Não se trata de uma avaliação moral da conduta de um de outro, e sim a retomada de um afirmação da sabedoria tradicional: o sábio terá sucesso, ao contrário do tonto, que fracassará $^{28}$.

Subitamente, porém, o v. 3 não fala mais de $k^{e}$ sîl - "estulto" e sim de $s \bar{a} k \bar{a} l$ - "idiota" 29 . Esta mudança logo após a afirmação da superioridade do coração/mente do sábio em relação ao coração/mente do estulto permite afirmar que aqui há aqui um jogo de palavras com as raízes $s k l$ - "ser idiota" e $s ́ k l$ - "ser prudente, ser perspicaz". Neste caso, Qohélet estaria atacando os pseudo-sábios de seu tempo, que acreditavam ter resposta a tudo, mas não ouviam a palavra dos profetas ${ }^{30}$. O referido jogo de palavras pode aplicar-se também a outros tipos de pseudo-sábios, como os que seguem cegamente a doutrina da retribuição e julgam as demais pessoas, ou até mesmo aos que, aderindo às correntes filosóficas gregas, desprezam a tradição de Israel ${ }^{31}$.

Qohélet qualifica o idiota com a frase enigmática - we'āmar lakōl $s \bar{a} k \bar{a} l$ h $\hat{u}$ ' - que admite duas leituras: "e diz (a respeito) de todos: ele (distributivo = cada um) é um idiota", bem como "e diz a todos que ele (mesmo) é um idiota". Não obstante os argumentos em favor da primeira ${ }^{32}$, talvez

28 Morla Asensio, Eclesiastés, 51.

29 único texto no qual ocorre a oposição hākām - "sábio" versus sākāl - “idiota" é 2,19. Nos demais, Qohélet usa sempre kêîl - "estulto".

30 Assim MANDRY, There is, nas páginas 267-269 da tese completa, não publicada. E mais adiante, à p. 273: “Aparentemente, Qohélet usa a palavra sākāl para designar os assim chamados sábios que são um tipo de mistura de hākām" com kêîl".

31 Sobre o helenismo e Qohélet, cf. a discussão em Vílchez Líndez, Ecclesiastes, 76-78; Kıм, Reanimating, 86-97. Sobre Qohélet como um cético, WEEKS, Ecclesiastes, particularmente o capítulo 5 (pp. 132-169).

32 Cf. discussão em Dı Fonzo, Ecclesiaste, 289-290, que opta pela primeira interpretação. Na mesma linha, GINSBURG, Coheleth, 426, segundo o qual, se o sentido fosse "diz a todos que ele mesmo é estulto", a construção seria kî sākāl hû' - "que ele (mesmo) é idiota" ou sākāl 'ănî - "eu sou idiota". Semelhantemente GLASSER, Processo, 189, que evoca Qo 2,2 para provar que 'mar l tem o sentido de "dizer de". Ainda nesta linha, Morla Asensio, Eclesiastés, 149, traduz "chama a todos de néscio"; mas, logo em seguida (p. 151), afirma que a tradução é duvidosa. Para a sintaxe, cf. WALTKE - O'CONNor, Introduction, $11.2 .10 \mathrm{~g}$ (p. 210). Os principais dicionários de hebraico anotam o significado "dizer (a respeito) de" para 'mar l, mas não citam Qo 10,3 como exemplo. Cf. Brown - Driver - Briggs, Lexicon, 56; Koehler - Baumgartner, Lexicon. I, 66 e CLINES, Dictionary. I, 322. 
haja uma ambiguidade proposital, como um elemento potenciador do texto, uma vez que, em ambas as interpretações, o resultado é o mesmo: o idiota se expõe ao ridículo, ao demonstrar a todos sua total incapacidade de discernir, principalmente quando quer se passar por sábio e menosprezar as demais pessoas.

\subsection{O discurso e a incapacidade do estulto-idiota: Qo 10,12-15}

Em 10,12-15, Qohélet retoma a crítica anteriormente feita ao tagarelar do estulto $(5,2-3 ; 7,5-6)$ e a aplica também ao idiota:

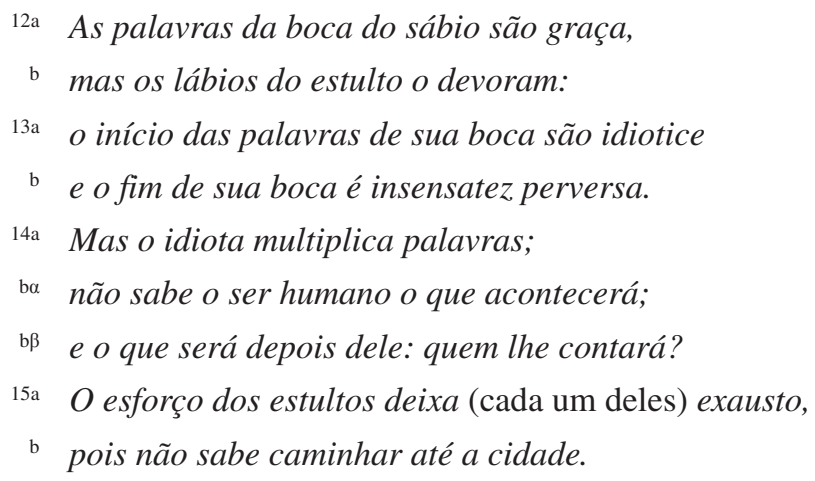

Em sua crítica final ao tonto, Qohélet elabora uma argumentação em dois pontos precisos: o discurso (vv. 12-14a) e a incapacidade (vv. 14b-15) do estulto.

O primeiro ponto é nitidamente marcado pelo campo semântico da palavra: $d \bar{a} b \bar{a} r$ - "palavra", peh - "boca" e śāpâ - "lábio". A superioridade do sábio sobre o estulto (v. 12) é o pano de fundo que explica por que os lábios deste último o devoram (v. 13) e, como uma conclusão para o argumento, de que forma o estulto deixa evidente sua tolice e/ou persiste nela (v. 14a). Com o merisma t’hilâ - "início" / 'ahăâît - "fim", Qohélet expressa sua convicção de que as palavras do estulto são sempre e irremediavelmente loucura ${ }^{33}$.

Como em 5,1-6, o desatino do estulto é evidenciado pelo seguinte fato: mesmo diante do resultado negativo provocado por suas palavras, ele continua a multiplicá-las. A mudança para $s \bar{a} k \bar{a} l$ - "idiota" evoca a siklût - "idiotice", como fonte e índole de seus discursos.

33 KRAŠOVEC, “Merism”, 239. 
O segundo ponto - a crítica à inaptidão do idiota (14bc-15) - é delimitada pela inclusão $l \hat{o}$ '-yēda - "não sabe (no imperfeito)" / lồ'-yāda - "não sabe (no perfeito)". A reflexão aqui desenvolvida já havia sido formulada em 6,12 e 8,7. O ponto de referência é a incapacidade de conhecer o que acontecerá no futuro. Tal limitação não é exclusiva do idiota, mas comum a toda a humanidade, e está expressa na questão retórica mî yagîd lô - "quem contará a ele?", que espera uma resposta negativa ${ }^{34}$ : ninguém pode predizer o futuro.

A presença do termo 'āmāl - "trabalho, esforço" assinala uma mudança de perspectiva: do conhecimento teórico (conhecer o que será) passa-se para o prático (saber fazer). Não obstante, ao estulto está reservada igual decepção: seu 'âmāl - "trabalho, esforço" o deixará exausto, mas não produzirá fruto algum (do mesmo modo como são infrutíferos os esforços do homem para conhecer o futuro). Ora, a sequência das frases "o homem não sabe" e "(o idiota) não sabe" oferece uma forte comparação: assim como o homem não tem capacidade para saber o que se dará depois dele, o estulto também não tem a capacidade de ir à cidade, isto é, resolver as questões cotidianas mais banais ${ }^{35}$, e por isso seu trabalho o deixa exausto. A argumentação é apresentada em um quiasmo:
14b:
não-saber teórico:
o ser humano não sabe (lô'-yēda ) o que acontecerá
14c: decepção:
e o que será depois dele, quem lhe contará?
15a: decepção:
o esforço dos estultos deixa (cada um deles) exausto,
15b:
não-saber prático:
pois não sabe (lô'-yāda ) caminhar até a cidade

Nada mal para uma última reprovação de um comportamento que o leitor/discípulo é incentivado a evitar!

${ }^{34}$ A expressão mîyagîd l - “quem contará para” é exclusiva de Qohélet e sempre arremata uma afirmação acerca da incapacidade humana de saber/conher algo: ninguém é capaz de transmitir tal informação. Cf. Qo 6,12; 8,7.

35 Para SACCHI, Qoelet, 208 [746], se “ir à cidade" for sinônimo de "estulto", a inteira frase se reduz uma tautologia - "o trabalho do estulto o cansa porque é um estulto" - e, por isso, tal interpretação deve ser descartada. Entretanto, caso se interprete lô'-yāda 'lāleket 'el-îr - "não sabe ir até a cidade", não como sinônimo de estulto, e sim como indicativo de uma incapacidade de ordem prática lideia reforçada pela presença do substantivo 'āmāl - "trabalho, esforço"), evita-se a tautologia e, mais ainda, o caráter do estulto ganha um novo atributo: a incompetência para afrontar os problemas do dia a dia e que não necessariamente exijam muita reflexão, tal como, ir até a cidade, "esforço" que, para alguém realizar, basta seguir a estrada! Nesta mesma linha, Delitzsch, Commentary, 385; e também Gordis, Koheleth, 324-325. 


\subsection{Síntese e paradoxos}

O $k^{e}$ sîl - "estulto" é o que é porque seu coração/mente gosta de tomar sempre a direção errada $(7,4 ; 10,2)$. Por conseguinte, suas palavras são muitas e vazias $(5,2)$, seu canto e sua gargalhada são barulho enganoso (7,5-6). Em razão desta sua inaptidão e superficialidade, as palavras e as ações do estulto têm um poder destruidor, para si mesmo $(4,5 ; 10,12.15)$ e para as outras pessoas $(5,1 ; 7,9)$, a ponto de provocar desgosto e repúdio até mesmo em Deus $(5,3)$. Qohélet, no entanto, encontra-se diante de um paradoxo: sem dúvida, é preferível ser sábio do que ser estulto $(2,14)$, assim como é preferível seguir o sábio do que o estulto $(4,13 ; 7,5 ; 9,17)$; não obstante, não há vantagem do sábio sobre o estulto $(6,8)$ e ambos partilham o mesmo destino de morte e esquecimento (2,15-16).

\section{O idiota}

Menos utilizado do que $k^{e} s \hat{l} l$ - "estulto", o termo sākāl - "idiota" (4 vezes: 2,$19 ; 7,17 ; 10,3.14)$, parece acrescentar alguma ênfase à crítica ao tonto, principalmente quando ambos os termos estão justapostos ou aplicados à mesma pessoa (os já analisados 10,2-3 e 10,12-15, respectivamente em 4.8 e 4.9).

\subsection{O herdeiro: sábio ou idiota?: Qo 2,19}

Após refletir sobre seu destino pessoal e chegar à triste conclusão que terá o mesmo fim do estulto, isto é, morte e esquecimento (2,14b-17), Qohélet se reconhece incapaz de suportar tal paradoxo e faz duas afirmações: "odiei a vida" (v. 17) e "odiei todo o meu trabalho" (v. 18). Tal sentimento leva Qohélet se questionar sobre seu herdeiro, e sua preocupação se torna ainda mais pungente. Qo 2,19:

\footnotetext{
19a E quem sabe se será sábio ou idiota?

E ele dominará sobre todo o fruto do meu esforço que fiz com esforço e fiz com sabedoria debaixo do sol.

b Isto também é vaidade!
}

O v. 12 anunciava dois temas que Qohélet desenvolve a seguir: a vantagem da sabedoria sobre a insensatez (vv. 13-17) e a incerteza concernente ao sucessor/herdeiro (vv. 18-23). Assim, no v. 19, ainda no âmbito da 
oposição sabedoria versus insensatez e idiotice, Qohélet questiona-se: A pessoa que herdará o que ele construiu, será alguém sábio ou idiota?

Nos vv. 18-20, o termo 'àmāl denota "fruto do esforço, resultado dos trabalhos" 36: Qohélet fala do que produziu e alcançou com sua fatiga, dedicação e sabedoria:

19 fiz com sabedoria
${ }_{21}$ com sabedoria, conhecimento e êxito

Tal efervescência dos vocábulos que indicam sabedoria é obscurecida por uma única menção ao idiota: um único herdeiro desse tipo pode pôr a perder a sabedoria, o conhecimento e o êxito de quem se esforçou toda a vida. Eis por que o tonto turba a tranquilidade de Qohélet e o leva a afirmar em seguida: "não há bem para o homem senão aproveitar do fruto de seu próprio trabalho" $(2,24)$. O homem sábio trata de aproveitar logo, antes que morra e deixe tudo para um sucessor, do qual desconhece a sabedoria ou a idiotice!

A resposta para uma pergunta iniciada por $m \hat{\imath}$-yôde $a$ "- "quem sabe?" é sempre negativa ${ }^{37}$ : "ninguém sabe", "não há quem possa saber". A angústia de Qohélet reside precisamente no fato de não poder conhecer a índole de seu herdeiro. Toda a dedicação e sabedoria de Qohélet se reduzem a hébel - "vaidade, mentira, vazio".

\subsection{Tolerância zero em relação ao idiota: Qo 7,16-17}

Em 7,15-18, Qohélet afirma já ter sido testemunha de um fato que contraria as máximas da doutrina tradicional da retribuição ${ }^{38}$ : a retidão não necessariamente traz a prosperidade, nem a maldade necessariamente traz o sofrimento e a morte ${ }^{39}$.

36 Cf. Gordis, Koheleth, 223; Vílchez Líndez, Ecclesiastes, 204. Para dicionários, cf. Clines, Dictionary. VI, 482; VanGemeren, Dictionary. III, 436.

37 CRENSHAW, “Expression”, divide as dez ocorrências da expressão em dois grupos, conforme a perspectiva proposta pela questão retórica: em cinco delas, “a porta está aberta" para uma resposta que possa mudar a situação para o bem do ser humano; as outras cinco aparentemente mantêm "a porta fechada" para qualquer ato de redenção (cf. pp. 274-275). Destas últimas, quatro encontram-se em Qohélet: 2,$19 ; 3,21 ; 6,12 ; 8,1$. A única exceção é $\operatorname{Pr} 24,22$.

38 Cf. Dt 4,40; Ex 20,12; Sal 1,8.14; 73,18; Pr 3,1-2; 4,10; 7,24-27; 21,21.

39 Cf. BRINDLE, “Righteousness”, 253 e 256. 
Os artifícios literários empregados nos vv. 16-17 têm finalidade enfática: é urgente que o discípulo/leitor evite aqueles dois enganos. Estes dois versículos seguem uma mesma organização, isto é, dois imperativos negativos, seguidos por uma oração final negativa ${ }^{40}$ :

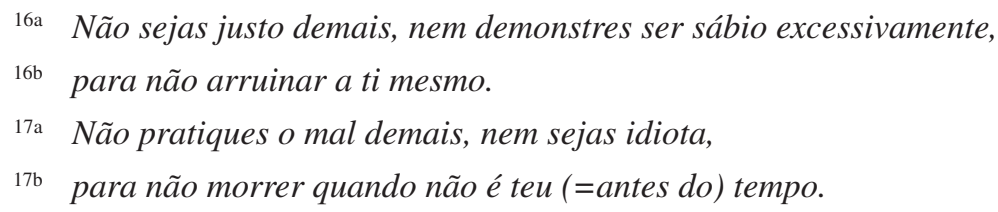

A recomendação $w^{e}$ 'al-tehî sākāl - "e não sejas idiota" é a única não reforçada por um advérbio. Omitindo-o, Qohélet deixa claro que, em sua opinião, o termo sākāl - "idiota" qualifica uma identidade que o discípulo/ leitor não deve absolutamente assumir. Em outras palavras, em determinadas circunstâncias e ocasiões, é admissível que alguém deixe de ser justo, é aceitável alguém que não demonstre ser sábio, é suportável alguém que aja com um pouco de maldade. Diante deste tipo de pessoas ou comportamentos, Qohélet se mostra complacente. Mas sua tolerância é zero em relação ao idiota, independentemente de ser muito ou somente um pouco idiota: este tipo de indivíduo é absolutamente intragável e a recomendação de Qohélet é categórica e irrestrita: "não sejas idiota"... em hipótese alguma ${ }^{41}$.

\subsection{Síntese e paradoxos}

O sākāl - "idiota" é um falastrão $(10,14)$ e tem um coração/mente tão distorcido, a ponto de pensar e afirmar que os outros é que são idiotas $(10,3)$. Por outro lado, ainda que ensine a seu discípulo que evite ser e se tornar idiota, e que para isso recorra ao argumento de que o idiota destrói a si mesmo $(7,17)$, Qohélet enfrenta novamente situações paradoxais: na so-

40 No texto hebraico, esta oração subordinada final negativa é construída com uma questão retórica: "Por que arruinarias a ti mesmo?"; "Por que morrer quando não é teu tempo?”. Cf. Joüon - Muraoka, Grammar, § 161h (p. 576); CLINES, Dictionary. IV, 551; Koehler - Baumgartner, Lexicon. I, 552.

41 Contra Ravası, Qohélet, 249, e Dı Fonzo, Ecclesiaste, 236, para os quais Qohélet recomenda uso moderado da estultícia. Com efeito, não se encontra em Qohélet a gradação muito/pouco estulto ou idiota; e exceto 10,1, nem mesmo a gradação maior/menor estultícia. Também Vílchez Líndez, Ecclesiastes, 312-313, nota 6, pensa que a ausência do advérbio indique que, para Qohélet, "ser néscio ou excessivamente néscio é a mesma coisa". 
ciedade, a idiotia recebe o poder que deveria ser concedido aos sábios $(10,6)$; no âmbito pessoal, vive a angústia de pensar que deixará tudo o que construiu em herança a um idiota $(2,19)$.

\section{Conclusão}

Como afirmado no início, este artigo foi uma tentativa de sistematizar o mosaico com o qual Qohélet retrata dois tipos de tonto: o $k^{e} s \hat{l} l$ - "estulto" e o $s \bar{a} k \bar{a} l$ - "idiota". Foi necessário, porém, abordar primeiramente os termos abstratos - hôlēlût / hôlēlôt - "insensatez", siklût - "idiotice", sékel "idiotismo" e késel - "estultice" - para compreender que há certa fusão dos traços psicológicos.

Qohélet não se contenta com uma discussão teórica; ao contrário, ele quer persuadir, levar à ação, fazer com que o discípulo/leitor tome uma firme postura de rejeição à insensatez e à idiotice, e se torne sábio. Para tanto, Qohélet insere a figura do tonto nos muitos contextos de seu discurso, associando-o às mais diversas circunstâncias da vida humana: o drama de viver e de morrer $(2,14 \mathrm{~b}-17 ; 6,8)$, o trabalho e o esforço $(4,5 ; 10,15)$, a religião $(4,17-5,6)$, as riquezas $(6,8)$, a herança $(2,19)$, a correção $(7,5-6)$, as consequências para a vida pessoal $(7,9.16-17 ; 10,1.12)$, as consequências para a sociedade $(4,13 ; 9,3.17 ; 10,6)$, os problemas sociais $(7,7-10 ; 10,5-7)$, a busca pela sabedoria e do sentido da vida $(1,17 ; 2,3.12 ; 7,25)$, o estilo geral de vida e de comportamento (2,13-14a; 7,2-4.15-18; 10,2-3.12-15). Em todas elas, o tonto - seja ele um estulto ou um idiota - é sempre identificado com o negativo, com o lado pior. tonto?

É inevitável, enfim, que surja a questão: Afinal de contas, quem é o

O tonto não é um doente mental, mas um indisciplinado, alguém a quem falta o discernimento prático e que crê, apesar de tudo, encontrar-se na via justa, insistindo no erro, justificando sua conduta; ou mesmo quando dotado de inteligência, não é capaz de utilizá-la para o bem. A arrogância do tonto tem um aspecto teológico: ele nega a existência de Deus (cf. Sal 14,1a) e, portanto, não é necessário temê-lo nem respeitar seus mandamentos. Eis porque insensatez (idiotice, tontice) muitas vezes é associada a falta de fé, pecado, culpa e injustiça (cf. Sal 69,6; Pr 24,9; Is 32,6; no NT, Mt 7,22).

Por tudo isso, não de pouca monta é o peso da figura do tonto no pessimismo de Qohélet, que afirma estar ciente de que igual esquecimento póstumo o igualará ao estulto $(2,12-17)$, de que um patrimônio construído 
com sabedoria e prudência pode acabar nas mãos de um estulto (2,18-23) e de que à idiotice se confere maior valor $(9,19-10,1)$ ou mais poder $(10,6)$ do que à sabedoria. Isso tudo explica por que Qohélet não tem o menor pudor em declarar repetidamente $(2,15.19 .21$ e 7,6$)$ que, também no que se refere ao tonto, a doutrina da retribuição é hébel, vaidade, engano, mentira!

Sobre este pano de fundo, devem ser avaliadas as divergentes afirmações acerca da vantagem ou não da sabedoria sobre a insensatez. O que à primeira vista pode ser considerado uma contínua contradição em Qohélet, na verdade é resultante de uma mudança de perspectiva: Qohélet não só cita afirmações da sabedoria tradicional para depois negá-la, como também reflete sobre os paradoxos que, em determinadas circunstâncias, eliminam a superioridade da sabedoria sobre a insensatez e, por conseguinte, do sábio sobre o tonto.

Não obstante (ou talvez, exatamente por isso), em seu desejo de persuadir, Qohélet elabora um ensinamento em forma de mosaico, no qual o tonto desempenha uma função didática de extrema importância: ele personifica todos os defeitos que o discípulo/leitor deve evitar, caso queira se tornar sábio. Ou seja, o tonto é o grande exemplo que deve ser muito bem observado e imitado às avessas.

É como se Qohélet dissesse ao seu discípulo/leitor:

- Queres ser sábio? Observa o tonto e faze o contrário!...

\section{Referências bibliográficas}

Albertz, R., " "צִ צ' 'q Gritar”, em E. Jenni - C. Westermann (eds.), Diccionario Teológico Manual del Antiguo Testamento. II, Madrid 1978, 715-723.

Anthonioz, St., O que é a sabedoria?, São Paulo 2017.

BRINDLE, W. A., "Righteousness and Wickedness in Ecclesiastes 7:15-18", Andrews University Seminary Studies 23 (1985) 243-257.

Brown, F. - Driver, S. R. - Briggs, C. A., A Hebrew and English Lexicon of the Old Testament, Oxford 1906.

Clines, D. J. A. (ed.), The Dictionary of Classical Hebrew, Sheffield 1993 2016.

Crenshaw, J. L., "The Expression Mî Yôdēa ' in the Hebrew Bible", Vetus Testamentum 36 (1986) 274-288. DOI: https://doi.org/10.2307/1518409; https://doi.org/10.1163/156853386X00339.

Delitzsch, F., Commentary on the Song of Songs and Ecclesiastes, Michigan 1980. 
Di Fonzo, L., Ecclesiaste, Torino 1967.

Gesenius, H. F. W. - Kautzsch, E. (eds.) - Cowley, A. E. (trad.), Gesenius' Hebrew Grammar, Oxford ${ }^{20} 1990$.

Gilbert, M., La Sapienza del cielo, Cinisello Balsamo 2005.

Ginsburg, Ch. D., Coheleth, commonly called the Book of Ecclesiastes, London 1861.

Glasser, E., O Processo da Felicidade por Coelet, São Paulo 1975.

Gordis, R., "The Social Background of Wisdom Literature", Hebrew Union College Annual 18 (1944) 77-118.

-, Koheleth, the Man and his World. A study of Ecclesiastes, New York 1968.

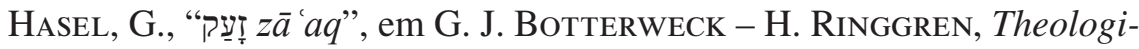
cal Dictionary of the Old Testament. IV, Grand Rapids 1980, 112-122.

Jenni, E., "שנא śn' Odiar”, em E. Jenni - C. Westermann (eds.), Diccionario Teológico Manual del Antiguo Testamento. II, Madrid 1978, 10491052.

Joüon, P. - Muraoka, T., A Grammar of Biblical Hebrew, Rome 2006.

KIM, J., Reanimating Qohelet's Contradictory Voices, Leiden - Boston 2018.

Koehler, L. - Baumgartner, W. (eds.), Hebrew and Aramaic Lexicon of the Old Testament, Leiden 2001.

Kон, Y.-V., Royal Autobiography in the Book of Qoheleth, Berlin 2006.

Koosed, J. L., (Per)mutations of Qohelet, New York 2006.

Krašovec, J., "Merism - Polar Expression in Biblical Hebrew", Biblica 64 (1983) 231-239.

Mandry, St. A., There is no God! A Study of the Fool in the Old Testament, particularly in Proverbs and Qoheleth, Roma 1972.

Morla Asensio, V., Eclesiastés, Estella 2018.

Nieto, F. - Cepeda, A. - Chávez, H. A., Introducción a la literatura sapiencial. Proverbios, Job, Qohélet, Sabiduría y Eclesiástico, Estella 2017.

Ogden, G. S., "The 'Better'-Proverb (Tôb-Spruch), Rhetorical Criticism, and Qoheleth", Journal of Biblical Literature 96 (1977) 489-505. DOI: https://doi.org/10.2307/3265988.

-, Qoheleth, Sheffield 1987.

PiotTi, F., “Osservazioni su alcuni problemi esegetici nel libro dell'Ecclesiaste", Bibbia e Oriente 20 (1978) 169-181.

-, "Osservazioni su alcuni problemi esegetici nel libro dell'Ecclesiaste (Studio II) - Il Canto degli Stulti (Qoh 7,5)”, Bibbia e Oriente 21 (1979) 129-140. Ravasi, G., Qohelet, Milano 1988.

SAcchi, P., Qoelet (Ecclesiaste), Milano 1986 [Reeditado em La Bibbia: Nuovissima versione dei testi originali. II - Antico Testamento, Milano 1991, 667-752]. 
SAKenfeld, K. D. (ed.), The New Interpreter's Dictionary of the Bible, Nashville 2008.

Silva, C. M. Dias da, "A função didática do tonto no livro de Qohélet: o idiota". In: Congresso Internacional da Sociedade de Teologia e Ciências da Religião - SOTER, 28, 2015, Belo Horizonte. Anais... Belo Horizonte: PUC-Minas, 2015, disponível em http://www.soter.org.br/anais/28. pdf, 161-165 [consulta: 22/03/2019].

-, "A função didática do tonto no livro de Qohélet", em Congresso da Associação Nacional de Pós-Graduação e Pesquisa em Teologia e Ciências da Religião - ANPTECRE, 5, 2015, Curitiba. Anais... Curitiba: PUCPR, 2015, disponível em: http://www2.pucpr.br/reol/pb/index.php/5anptecre?dd1=15454\&dd99=view \&dd98=pb [consulta: 22/03/2019].

-, "Universos virtuais bíblicos", Estudos Bíblicos 107 (2010) 63-74.

Silva, C. M. Dias da - Ló, R. de C., Caminho não muito suave: Cartilha de literatura sapiencial bíblica, Campinas 2011.

TAmez, E., Cuando los horizontes se cierran, San José 1998.

VanGemeren, W. A. (ed.), New International Dictionary of Old Testament Theology and Exegesis, Grand Rapids 1997.

Vílchez Líndez, José, Ecclesiastes ou Qohélet, São Paulo 1999.

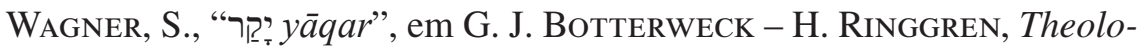
gical Dictionary of the Old Testament. VI, Grand Rapids 1990, 278-287.

Waltke, B. K. - O'Connor, M. P., An Introduction to Biblical Hebrew Syntax, Indiana 1990.

WeEKs, St., Ecclesiastes and Scepticism, London 2012.

Zlotowitz, M., Kohélet: L'Ecclesiaste. Traduction et commentaires fondés sur les sources talmudiques, midrachiques et rabbiniques, Paris 1987.

[recibido: 23/3/2019 - aceptado: 09/09/19] 